\title{
Preparation and Characterization of Titania Microspheres and Their Application in a Liquid Chromatography Stationary Phase
}

\author{
Jie Zhang1,2, Xiaoshu Zhu1,2, Yinping Zhang1,2* \\ ${ }^{1}$ Analysis \& Testing Center, Nanjing Normal University, Nanjing, China \\ ${ }^{2}$ Key Lab of Biofunctional Materials of Jiangsu Province, Nanjing, China \\ Email: ${ }^{\star}$ zhangyinpingnjnu@163.com
}

How to cite this paper: Zhang, J., Zhu, X.S. and Zhang, Y.P. (2016) Preparation and Characterization of Titania Microspheres and Their Application in a Liquid Chromatography Stationary Phase. Journal of Crystallization Process and Technology, 6, 2128. http://dx.doi.org/10.4236/jcpt.2016.63003

Received: July 14, 2016

Accepted: July 26, 2016

Published: July 31, 2016

Copyright $\odot 2016$ by authors and Scientific Research Publishing Inc. This work is licensed under the Creative Commons Attribution International License (CC BY 4.0).

http://creativecommons.org/licenses/by/4.0/ (c) (i) Open Access

\begin{abstract}
Titania microspheres were synthesized using hydrothermal methods to exploit a new liquid chromatography stationary phase. The prepared titania microspheres were approximately $7 \mu \mathrm{m}$ in diameter, and the particle size distribution was relatively narrow and uniform. Furthermore, the average specific surface area was $276.0 \mathrm{~m}^{2} \cdot \mathrm{g}^{-1}$, the average pore volume was approximately $0.25 \mathrm{~mL} \cdot \mathrm{g}^{-1}$, and the pore diameter was approximately $35.9 \mathrm{~nm}$ for sintering titania microspheres. These parameters indicate that the titania microspheres prepared for this study have excellent surface properties for chromatography. Additionally, columns filled with the titania microspheres were able to separate basic compounds, including benzene, nitrobenzene and o-nitroanisole. It could be proposed that the titania microspheres prepared for this study would be a promising stationary phase for liquid chromatography.
\end{abstract}

\section{Keywords}

Hydrothermal Method, Porous Materials, Titania Microspheres, Sintering, Liquid Chromatography Stationary Phase, Surfaces

\section{Introduction}

High-performance liquid chromatography (HPLC) has been widely accepted as one of the main analytical techniques for organic compounds [1]. The stationary phase filled in the column is the main determinant for HPLC separations. Over the past few decades, the properties and performance of stationary phases have been significantly enhanced [2] [3], but silica is still the most popular packing material for HPLC columns because it can prolong organosilane chains. However, a silica stationary phase can only 
be used over a narrow $\mathrm{pH}$ range $(\mathrm{pH} 3$ - 10) because of its strong hydrolysis and unstable Si-O band; it can even irreversibly adsorb alkaline compounds, limiting its application in some special fields.

Recently, an increasing number of metal oxide materials have been tested for HPLC column preparation [4] [5]. Metal oxides can behave as amphoteric ion exchangers, meaning that they can act as cation and anion exchangers down to a $\mathrm{pH}$ of 1 and up to a $\mathrm{pH}$ of 14. Titania not only displays amphoteric ion-exchange properties but also has good chemical stability, mechanical strength and enough rigidity [5] [6] to make it an excellent stationary phase material for HPLC columns. A series of titania nanotubes or microspheres have been prepared using the sol-gel method [7], polymerization-induced colloid aggregation [8], and non-aqueous emulsions or co-precipitation. Furthermore, the titania microspheres have been used for HPLC chromatographic packing. However, the methods mentioned above are too complicated, and the material and reagents too expensive to be applied extensively. Conversely, hydrothermal processing is a promising approach due to its simplicity, fast reaction kinetics and low cost [9] and could create new possibilities for high surface area and large pore diameter titania morphologies.

This study was intended to test the hypothesis that titania microspheres synthesized by the hydrothermal method could display excellent surface parameters, an ideal mesopore structure, and the narrow size distribution needed for the HPLC stationary phase. Optimal experimental conditions for synthesizing titania microspheres were found. Furthermore, to test the chromatographic performance, the prepared titania microspheres were employed as the HPLC stationary phase to separate some basic compounds.

\section{Experimental Section}

\subsection{Reagents}

The titanium tetrachloride used as a precursor for the reaction was purchased from Sinopharm Chemical Reagent Company (Beijing, China); the ethanol and n-hexane used as the mobile phase were purchased from Tedia Company (USA). Ammonium sulfate, urea and other analytical grade reagents were obtained from Shanghai Chemical Reagent Company (Shanghai, China).

\subsection{Synthesis of Titania Microspheres}

To synthesize uniform titania microspheres, $0.72 \mathrm{~g}$ of ammonium sulfate, $8.5 \mathrm{~g}$ of urea, $8.0 \mathrm{~mL}$ of millipore water and $8.0 \mathrm{~mL}$ of ethanol were added into a $50-\mathrm{mL}$ conical beaker. The mixture was homogeneously stirred, and an aliquot of $0.6 \mathrm{~mL}$ of titanium tetrachloride was added drop by drop while continually stirring for $5 \mathrm{~h}$. A transparent solution with a $\mathrm{pH}$ value of approximately 2.0 was then obtained and transferred into 50-mL polyfluortetraethylene cups that were heated at $393 \mathrm{~K}$ for $5 \mathrm{~h}$ in an oven (DGF30, Nanjing, China). Finally, the suspension was filtered, and the precipitate was washed twice with millipore water and ethanol, respectively. The prepared methods 
need high temperature over $500 \mathrm{~K}$, thus the microspheres obtained from the precipitate were finally ground, dried at $353 \mathrm{~K}$ and carbonized at $773 \mathrm{~K}$ in a muffle furnace for subsequent characterization.

\subsection{Characterization of the Synthesized Titania Microspheres}

The morphology of the titania microspheres was observed using a scanning electron microscope (SEM, JSM-5610LV, Japan). The crystal shape of the titania microspheres was determined using an X-ray diffractometer (D/max-2500 VL/PC, Japan). A micromeric model ASAP-2010 surface analysis instrument (Micromeric Corporation, USA) was employed to generate nitrogen adsorption/desorption isotherms. A laser particle size analyzer, model Master Sizer2000 (Malvern Company, U.K) was used to determine the particle size distribution (PSD).

\subsection{Column Packing and Its Performance}

The chromatographic column $(250 \times 4.6 \mathrm{~mm}$ i.d. $)$ was filled with the prepared titania microspheres as the stationary phase at a pressure of 450 psi using a high-pressure pump (STV-150, USA). During the filling procedure, a mixture of isopropanol and methanol were used as the propulsion solvent. The performance of the columns was tested by separating special basic substances with an HPLC/MS (1290 - 6460, Agilent Corporation, American).

\section{Results and Discussion}

\subsection{SEM Images and X-Ray Diffraction of Titania Microspheres}

Titania microspheres were synthesized using the hydrothermal method. The morphology was characterized, as shown in Figure 1. The particle size distribution of the prepared titania microspheres was narrow, and the particle diameters were in the range of

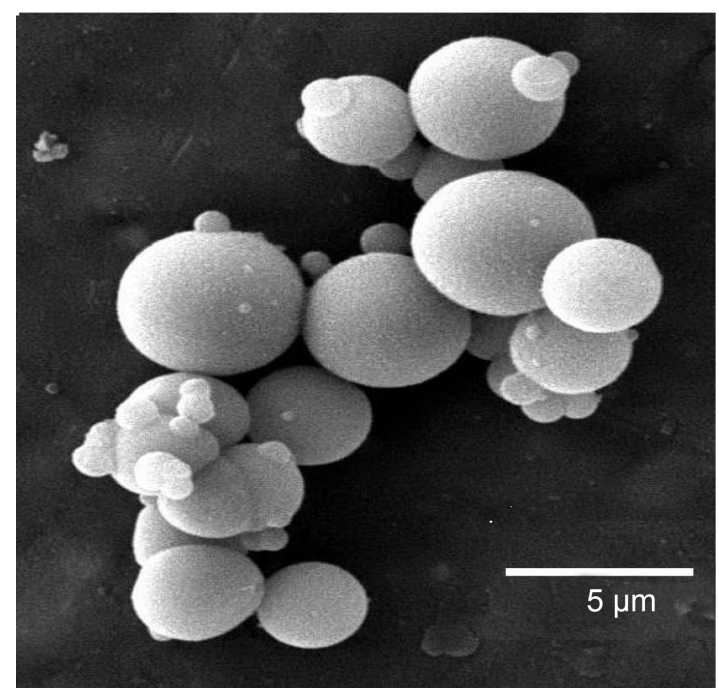

Figure 1. SEM image of the prepared titania microspheres. 
$6-10 \mu \mathrm{m}$. Further analysis of the particle size distribution showed that the average diameter of the titania microspheres was $7 \mu \mathrm{m}$.

Furthermore, the titania microspheres were characterized by X-ray diffraction (Figure 2). Apparently, the X-ray diffraction intensity of the titania microspheres that did not undergo heat treatment was very low, and the microspheres had an amorphous crystal structure. However, after being sintered at $500^{\circ} \mathrm{C}$, the diffraction intensity of the titania microspheres sharply increased, and diffraction peaks clearly appeared at $25.32^{\circ}$, $37.88^{\circ}, 48.11^{\circ}, 53.94^{\circ}$, and $62.51^{\circ}$, proving that the sintered material belonged to anatase-type of titania.

\subsection{Surface Properties of the Titania Microspheres}

It is critical for chromatographic columns to have enough free space available to provide a sufficient separation efficiency; this requires that the packing material have a large surface area to facilitate carrying large numbers of samples [4]. The sintered titania microspheres had smaller specific surface areas than the un-sintered microspheres. The specific surface area of the sintered titania microspheres was found to be 276.0 $\mathrm{m}^{2} \cdot \mathrm{g}^{-1}$, using the standard Brunauer Emmett Teller (BET) method, whereas the microspheres that were not heat treated had a surface area of $383.5 \mathrm{~m}^{2} \cdot \mathrm{g}^{-1}$. This could be attributed to the aqueous phase bound to the titania microspheres. At high temperatures, it is possible that the aqueous phase dissociated out of the compound and the adjacent Ti-OH bond condensed to form a Ti-O-Ti bond [10], thus leading to a decrease in the specific surface areas. However, the crystal surfaces that tended to be formed with the heat treatments were consistent with the surfaces of the elementary lattice cells. Thus,

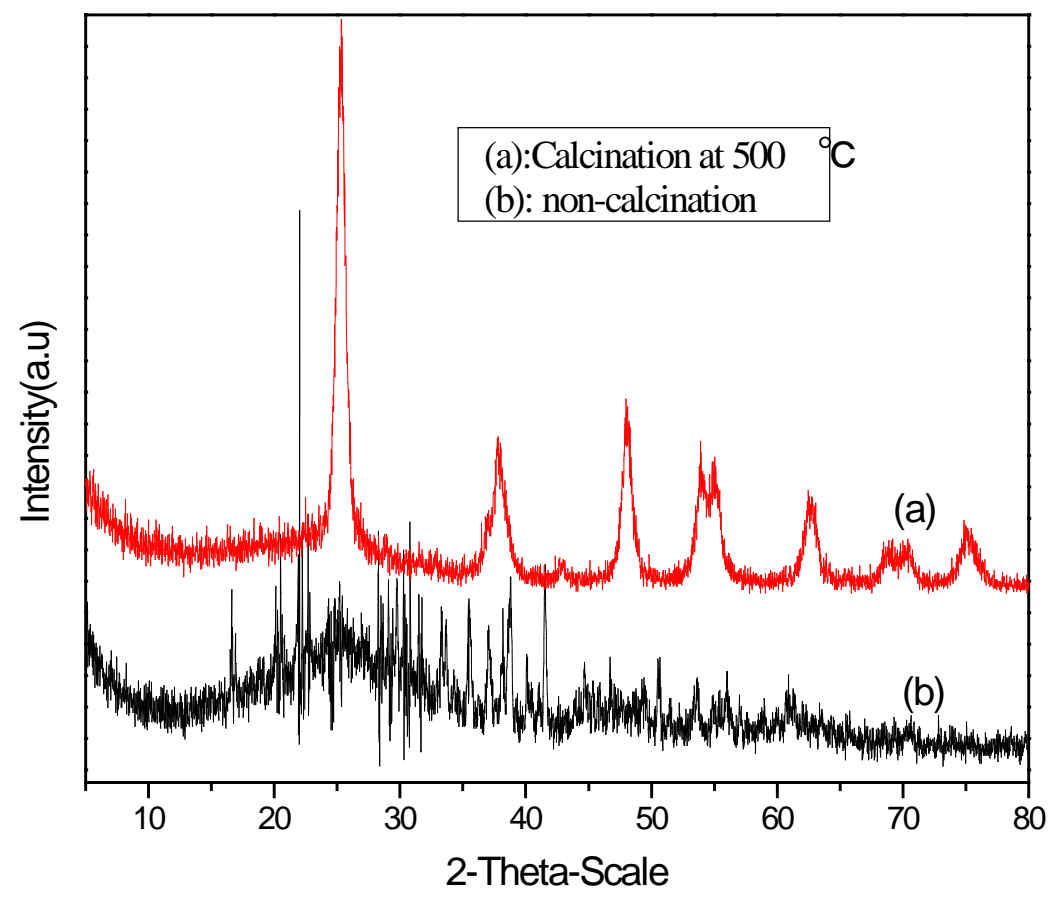

Figure 2. XRD patterns of the titania microspheres. 
the sintered titania microspheres surfaces were more homogeneous, which is one of the physical requirements for the HPLC stationary phase.

As suggested by Thekkudan et al. [11], ideal packing should be in accordance with suitable physical and chemical parameters. The packing can be described by the porosity of the material, which is generally determined by nitrogen adsorption and desorption from the microspheres after heat treatment. As shown in Figure 3, the adsorption branch was a IV-like isotherm and displayed an $\mathrm{H}$ type hysteresis loop, indicating the presence of a well-developed mesoporosity in the titania microspheres. Furthermore, according to the desorption isotherm, the average pore volume of the titania microspheres was approximately $0.25 \mathrm{~mL} \cdot \mathrm{g}^{-1}$, and the average pore diameter was approximately $35.9 \mathrm{~nm}$ based on the Barret-Joyner-Halenda (BJH) models. These results correlate well with the report that the pore diameter of microspheres must be in the range of 2 to $50 \mathrm{~nm}[12]$.

\subsection{Chromatographic Condition}

Normal-phase separation of the aromatic compounds was performed on the packed titania column. It was found that there was $10 \mu \mathrm{l} \cdot \mathrm{mL}^{-1}$ benzene, $0.4 \mu \mathrm{l} \cdot \mathrm{mL}^{-1}$ nitrobenzene and $0.2 \mu \mathrm{l} \cdot \mathrm{mL}^{-1} \mathrm{o}$-nitroanisole. These compounds were detected at $254 \mathrm{~nm}$, and the mobile phase was a combination of $n$-hexane and ethanol with a gradient elution containing $10 \%$ ethanol at $7 \mathrm{~min}$ with a rate of $0.6 \mathrm{~mL} \cdot \mathrm{min}^{-1}$. The column temperature was controlled to be $35^{\circ} \mathrm{C}$, and the initial pressure of the column was approximately 280 bar. As shown in Figure 4, all of the substances were well separated on the titania column. Benzene and nitrobenzene were retained on the stationary phase as a Lewis base.

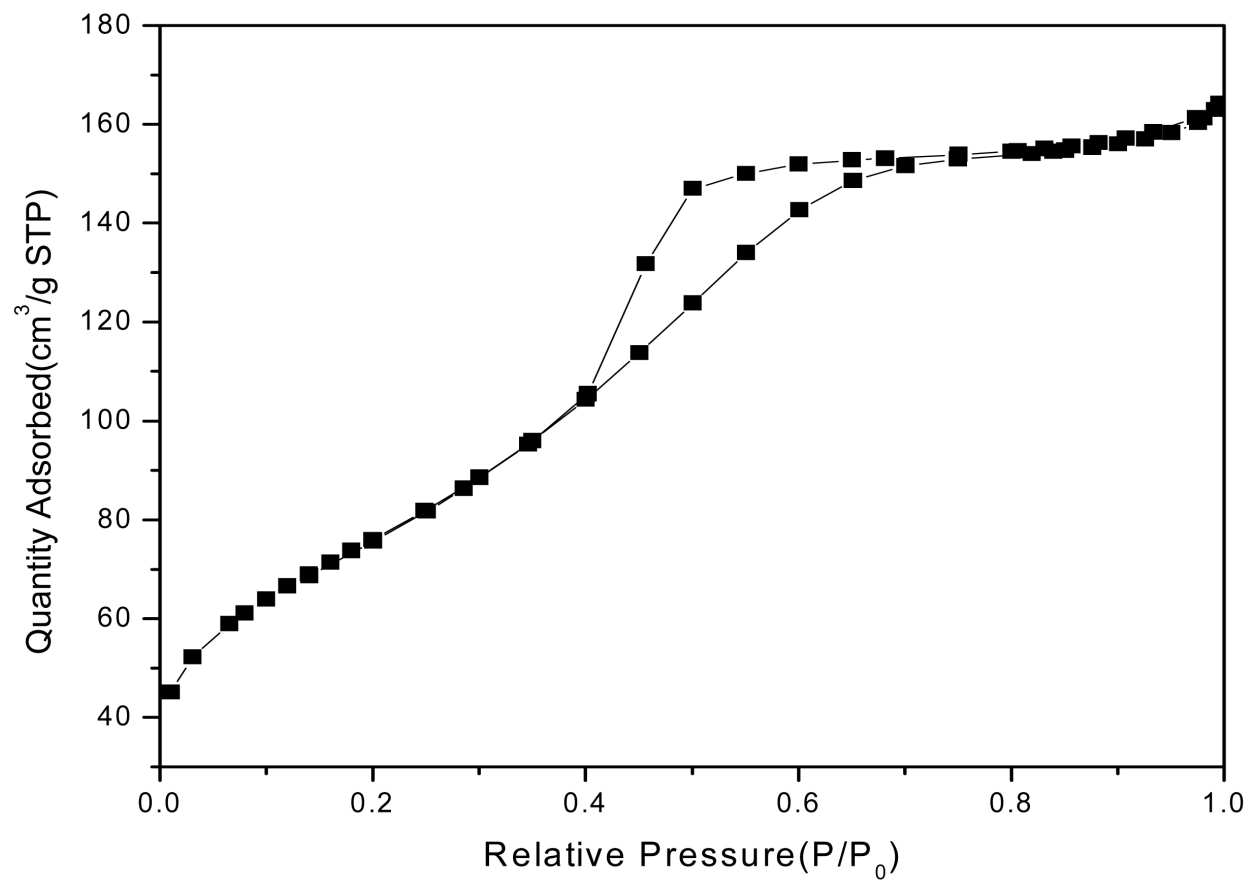

Figure 3. Nitrogen adsorption and desorption isotherms of the titania microspheres. 


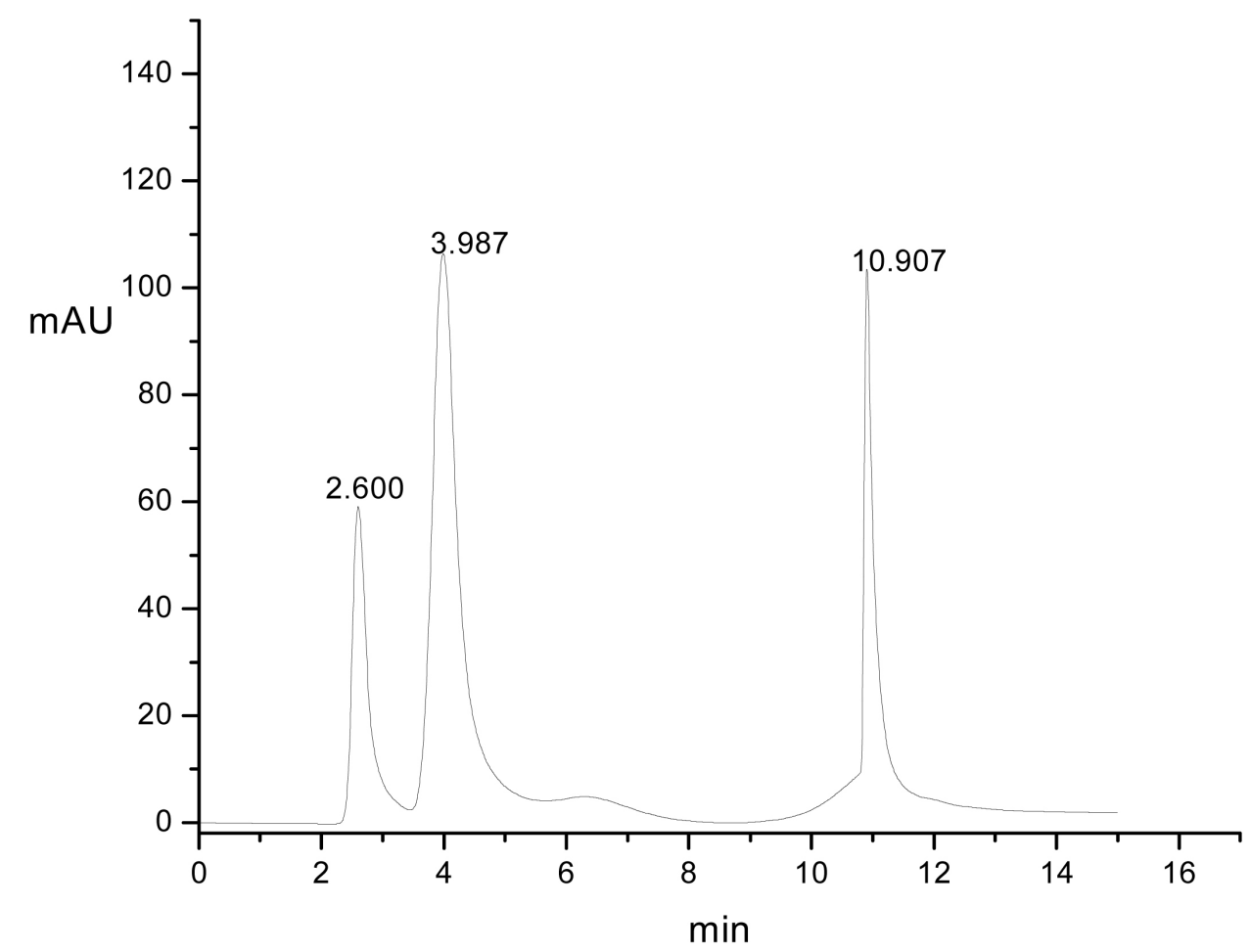

Figure 4. Chromatogram of the separation of the aromatic compounds with the titania microspheres as the stationary phase $(250 \times 4.6 \mathrm{~mm}$ i.d.). Solute: benzene (eluting at $2.6 \mathrm{~min})$, nitrobenzene (eluting at $3.9 \mathrm{~min}$ ), o-nitroanisole (eluting at $10.9 \mathrm{~min}$ ). Eluent: $\mathrm{n}$-hexane and ethanol. Flow: $0.6 \mathrm{~mL} \cdot \mathrm{min}^{-1}$. Detection: UV at $254 \mathrm{~nm}$. Temperature: $35^{\circ} \mathrm{C}$. Pressure: 280 bar.

The $\pi$ electron of these molecules can react with the weakly acidic surface of titania microspheres [13]. However, due to the strong polarity, the o-nitroanisole was retained much longer in the chromatographic column. Furthermore, the filled chromatographic column could be reused for separating these basic compounds. Thus, the titania that was synthesized by the hydro-thermal method was considered to be a promising material for the HPLC stationary phase.

\section{Conclusion}

Traditional silica columns would lead to a larger solubility in the basic mobile phases at higher temperatures. Simultaneously, tailed peaks appeared when alkaline substances were separated on a silica column. Thus, our work focused on exploring a new liquid chromatography stationary phase. The titania microspheres synthesized using hydrothermal treatments were approximately $7 \mu \mathrm{m}$ in diameter and had a relatively narrow and uniform particle size distribution. The pore size of the titania microspheres was in the range of mesopores; the average specific surface area was $276.02 \mathrm{~m}^{2} \cdot \mathrm{g}^{-1}$, and the average pore volume was $0.25 \mathrm{~cm}^{3} \cdot \mathrm{g}^{-1}$. Furthermore, benzene, nitrobenzene and o-nitroanisole all separated easily in the titania column. All of the parameters highlighted above indicate that titania microspheres prepared using a hydrothermal method would provide an excellent normal phase for liquid chromatography. 


\section{Acknowledgements}

This work was financially supported by the Natural Science Foundation of Jiangsu Province (13KJB150023, 15KJB210003, BK20150976), and the Natural Science Foundation of China (41501239).

\section{References}

[1] Lqbal, M.A., Szulejko, J.E. and Kim, K.H. (2014) Determination of Methylamine, Dimethylamine, and Trimethylamine in Air by High-Performance Liquid Chromatography with Derivatization Using 9-Fluorenylmethylchloroformate. Analytical Methods, 6, 5697-707. http://dx.doi.org/10.1039/C4AY00740A

[2] Gouda, A.A., Hashem, H. and Jira, T. (2014) Spectrochimica Acta. Part A, Molecular and Biomolecular Spectroscopy. Spectrochimica Acta Part A: Molecular and Biomolecular Spectroscopy, 130, 480-487.

[3] Ilisz, I., Grecso, N., Palko, M., Fulop, F., Lindner, W. and Peter, A. (2014) Structural and Temperature Effects on Enantiomer Separations of Bicyclo[2.2.2] octane-based 3-amino-2carboxylic Acids on cinchona Alkaloid-Based Zwitterionic Chiral Stationary Phases. Journal of Pharmaceutical and Biomedical Analysis, 98, 130-139.

http://dx.doi.org/10.1016/j.jpba.2014.05.012

[4] Amparo, M.R., Marques, F.A. and Faria, A.M. (2013) Synthesis and Characterization of a Novel Stationary Phase, Si-Zr/Ti(PMTDS), Based upon Ternary Oxide Support for High Performance Liquid Chromatography. Journal of the Brazilian Chemical Society, 24, 15121519.

[5] El Debs, R., Jaoude, M.A., Morin, N., Miege, C. and Randon, J. (2011) Retention of $\beta$ Blockers on Native Titania Stationary Phase. Journal of Separation Science, 34, 1805-1810. http://dx.doi.org/10.1002/jssc.201100259

[6] Renuka, N.K., Praveen, A.K. and Aravindakshan, K.K. (2013) Synthesis and Characterisation of Mesoporous Anatase $\mathrm{TiO}_{2}$ with Highly Crystalline Framework. Materials Letters, 91, 118-120. http://dx.doi.org/10.1016/j.matlet.2012.09.110

[7] Yeh, S.W., Ko, H.H., Chiang, H.M., Chen, Y.L., Lee, J.H. and Wen, C.M. (2014) Characteristics and Properties of a Novel in Situ Method of Synthesizing Mesoporous $\mathrm{TiO}_{2} \mathrm{Nano-}$ powders by a Simple Coprecipitation Process without Adding Surfactant. Journal of Alloy Compounds, 613, 107-116. http://dx.doi.org/10.1016/j.jallcom.2014.05.227

[8] Huai, Q.Y. and Zuo, Y.M. (2009) Synthesis of Porous Titaniaspheres for HPLC by Polymerization-Induced Colloid Aggregation (PICA) Using tert-n-Butyl Titanate. Journal of Analytical Chemistry, 64, 176-180. http://dx.doi.org/10.1134/S1061934809020142

[9] Truong, D., Kobayashi, M., Kato, H. and Kakihana, M. (2011) Hydrothermal Synthesis of Hierarchical $\mathrm{TiO}_{2}$ Microspheres Using a Novel Titanium Complex Coordinated by Picolinic Acid. Journal of the Ceramic Society of Japan, 119, 513-516.

http://dx.doi.org/10.2109/jcersj2.119.513

[10] Arami, H., Mazloumi, M., Khalifehzadeh, R. and Sadmezhaad, S.K. (2007) Sonochemical Preparation of $\mathrm{TiO}_{2}$ Nanoparticles. Materials Letters, 61, 4559-4561. http://dx.doi.org/10.1016/j.matlet.2007.02.051

[11] Thekkudan, D.F., Rutan, S.C. and Carr, P.W. (2010) A Study of the Precision and Accuracy of Peak Quantification in Comprehensive Two-Dimensional Liquid Chromatography in Time. Journal of Chromatography A, 1217, 4313-4327. http://dx.doi.org/10.1016/j.chroma.2010.04.039 
[12] Thompson, J.D. and Carr, P.W. (2002) A Study of the Critical Criteria for Analyte Stability in High-Temperature Liquid Chromatography. Analytical Chemistry, 74, 1017-1023. http://dx.doi.org/10.1021/ac010917w

[13] Winkler, J. and Marme, S. (2000) Titania as a Sorbent in Normal-Phase Liquid Chromatography. Journal of Chromatography $A, \mathbf{8 8 8}, 51-62$.

http://dx.doi.org/10.1016/S0021-9673(00)00489-1

Submit or recommend next manuscript to SCIRP and we will provide best service for you:

Accepting pre-submission inquiries through Email, Facebook, LinkedIn, Twitter, etc. A wide selection of journals (inclusive of 9 subjects, more than 200 journals)

Providing 24-hour high-quality service

User-friendly online submission system

Fair and swift peer-review system

Efficient typesetting and proofreading procedure

Display of the result of downloads and visits, as well as the number of cited articles Maximum dissemination of your research work

Submit your manuscript at: http://papersubmission.scirp.org/ 